\title{
URBAN AREA CHANGE DETECTION USING TIME SERIES AERIAL IMAGES
}

\author{
C. Altuntas ${ }^{1, *}$ \\ ${ }^{1}$ Selcuk University, Engineering Faculty, Department of Geomatics, 42075 Selcuklu Konya, Turkey - caltuntas@ selcuk.edu.tr
}

\author{
Commission II, WG II/4
}

KEY WORDS: Photogrammetry, Dense Point Cloud, Aerial Image, Historical Image, Urban Change Detection

\begin{abstract}
:
The urban area should be imaged in three-dimensional (3D) for planning, inspection and management. In addition fast urbanisation requires detection the urban area changes which have been occurred with new buildings, additional floor to current buildings and excavations. 3D surface model of urban area enables to extracting high information from them. On the other hand high density spatial data should be measured to creating 3D digital terrain surface model. The dense image matching method makes 3D measurement with high density from the images in a short time. The aim of this study is detection the urban area changes via comparison of time series point cloud data from historical stereoscopic aerial images. The changes were detected with the difference of these digital elevation models. The study area was selected from Konya city in Turkey, and it has a large number of new buildings and changes in topography. Dense point cloud data were created from historical aerial images belong to years of 1951, 1975 and 2010. Every threedimensional point cloud data were registered to global georeferenced coordinate system with ground control points created from the imaged objects such as building corner, fence, wall and etc. Then urban changes were detected with comparing the dense point cloud data by exploiting the iterative closest point (ICP) algorithm. Consequently, the urban changes were detected from point to surface distances between image based point clouds.
\end{abstract}

\section{INTRODUCTION}

Three-dimensional (3D) point cloud creation gets standard method for measurement, 3D modelling and shape visualization. 3D point cloud data enables to acquiring high information from the measurement area. Digital elevation model, perspective image, cross section and other geometric information related to the measurement area can be extracted from the point cloud. Moreover, point cloud data can be imaged in different mode. 3D point cloud is obtained from aerial and terrestrial LIDAR, mobile LIDAR, SAR measurement, range camera, dense image matching and other $3 \mathrm{D}$ measurement techniques.

The photogrammetric measurement technique has been changed by the time with cooperation to scientific developments. Today spatial data measurement from stereoscopic images can be performed automatically. Furthermore high density spatial data can be created from stereoscopic images with this procedure in a short time. This accomplishment on the process creates opportunity to use the photogrammetry in a wide variety of applications. The images from aerial and unmanned aerial vehicles or terrestrial cameras can be used to creating point cloud data. Furthermore mobile phone images are also used to creating point cloud data. Harvin and Lucier (2012) investigated the accuracy of dense point cloud by comparing ground control point (GCP) coordinates with the check point coordinates measured based on traditional terrestrial method. The GCP positions had been estimated with $2-3 \mathrm{~cm}$ accuracy from the images taken forty meters height. Barazzetti et al (2010) used to dense image matching for creating three dimensional model of cultural objects and buildings. In another study, canopy heights were estimated from digital surface model generated via dense point cloud from images of unmanned aerial vehicle (Jensen and Mathews, 2016). Building change detection was also detected from historical aerial photographs by creating dense point clouds. The combination of image-based dense digital surface model reconstruction from historical aerial imagery with object-based image analysis was used for the detection of individual buildings and the subsequent analysis of settlement change (Nebiker et al., 2014). The other study introduced building change detection comparing old dense point cloud and new LIDAR images (Du et al., 2016).

The change detection by comparing two point clouds is performed with point to mesh (triangle) distances (Xiao et al., 2015; Awrangjeb et al., 2015; Barnhart and Crosby, 2013), filtering ( $\mathrm{k}-\mathrm{d}$ tree, voxel, regular grid, etc.) (Scaioni et al., 2013), machine learning (Tran et al., 2018) and iterative closest point (ICP) algorithm (Zhang et al., 2015). Point to triangle method tackles irregular point density and occlusion problems, also eliminates false detections on penetrable objects. Urban object changes are automatically detected at point level in complex street environments. The limitation of the method is that objects replaced by another can not be detected. Small changes in short time period and big changes in large time periods data can be detected with point to triangle method (Xiao et al., 2015; Barnhart and Crosby, 2013). The measurement data are resampled as regular grid to analyse the change with the grid method. The grid anomalies have been compared to detect the changes in time series measurement data (Scaioni et al., 2013). Tran et al (2018) exploited machine learning technique to object classification and change detection in 3D data. The study area was defined in eight classes, and the final result was achieved an overall accuracy of over $90 \%$ for both epochs of eight classes. In addition, the ICP (Chen and Medioni, 1992) and its variants had been used for change detection in many studies. The changes bring on earthquake had been detected from two time series LIDAR point cloud by using anisotropic-weighted ICP. The registration of two LIDAR data sets had been accomplished with 0.44 meters error using the ICP variant (Zhang et al., 2015). More information about change detection approaches can be found on Tran et al (2018).

\footnotetext{
* Corresponding author
} 
In this study changes in urban area of Konya city were estimated by using dense point cloud data created from time series aerial images. The changes are in vertical direction and it was detected by comparing the created three dimensional point clouds using ICP algorithm. Hereby unauthorized constructions and excavations can be detected by the authorities with comparison of time period data.

\section{DATA and METHOD}

The study area was selected from centre of Konya city in Turkey (Figure 1). It has industrial and settlement areas including high buildings (twelve floors). The historical aerial images belong to years of 1951, 1975 and 2010 were obtained from Turkish General Command of Mapping. The images concerning the year of 1951 and 1975 had been taken by analogue film cameras and then it had been digitized with micro film scanner. The analogue cameras have grey scale colour images. Micro film scanner offers to select of pixel dimensions in scanning. The images of 1951 and 1975 were scanned with 21 and 15 micron pixel dimensions respectively. On the other hand the calibration parameters of the analogue cameras are not known before the process. The images of the year 2010 had been recorded by digital camera (Table 1).

\begin{tabular}{|c|c|c|c|}
\hline $\begin{array}{l}\text { Specificati } \\
\text { ons }\end{array}$ & Date 1951 & Date 1975 & Date 2010 \\
\hline Type & Analog & Analog & Digital \\
\hline $\begin{array}{l}\text { Focal } \\
\text { length } \\
\text { (mm) }\end{array}$ & 204.18 & 208.17 & 100.50 \\
\hline $\begin{array}{l}\text { Flight } \\
\text { height (m) }\end{array}$ & 6270 & 7250 & 8050 \\
\hline $\begin{array}{l}\text { Image } \\
\text { scale }\end{array}$ & 30708 & 20000 & 80099 \\
\hline $\begin{array}{l}\text { Image } \\
\text { Dimension }\end{array}$ & $\begin{array}{l}18 \mathrm{~cm} \times 18 \mathrm{~cm} \\
9216 \times 9344 \\
\text { pixels }\end{array}$ & $\begin{array}{l}18 \mathrm{~cm} \times 18 \mathrm{~cm} \\
12032 \times 117 \\
76 \text { pixels } \\
\end{array}$ & $\begin{array}{l}9420 \times 144430 \\
\text { pixels }\end{array}$ \\
\hline $\begin{array}{l}\text { Image area } \\
\left(\mathrm{km}^{2}\right)\end{array}$ & 46.39 & 23.01 & 34.26 \\
\hline $\begin{array}{l}\text { stereoscopi } \\
\text { c area } \\
\left(\mathrm{km}^{2}\right) \\
\end{array}$ & 27.6 & 22.7 & 21.7 \\
\hline $\begin{array}{l}\text { Pixel } \\
\text { dimensions } \\
\text { (micron) }\end{array}$ & 21 & 15 & 7.2 \\
\hline $\begin{array}{l}\text { GSD } \\
(\mathrm{cm} / \text { pix })\end{array}$ & 73.4 & 40.3 & 50.2 \\
\hline $\begin{array}{l}\text { Flying } \\
\text { route }\end{array}$ & S-N & W-E & W-E \\
\hline
\end{tabular}

Table 1. The specifications of aerial images used in this study

The date of 1951 and 2010 have two stereoscopic images, and the date of 1975 has three stereoscopic images that have $70 \%$ overlap on forward direction. The orientation parameters of these images are not known before the process.

Dense point cloud data were created without camera calibration parameters. Thanks to its easy application, dense point cloud creation from stereoscopic images is used in a wide variety of applications that require 3D spatial data. All amateur camera images can be used to creating a dense point cloud by using structure from motion (SfM) photogrammetry. Furthermore, mobile phones and other sources of imagery can also be used for this purpose.
The created dense point clouds were registered to geodetic coordinate frame. Since there were not any GCP, that have specific shapes and coordinates, signalized on the ground before taken the images, significant object details such as building corner, garden wall, road intersections, fences and etc. were used as GCPs (Figure 2). Therefore set up the GCPs is very hard especially for old date images. The founded control points should be selected from aerial images of old date and already present on the ground. Nevertheless we could establish enough GCPs for the registration. The study area of Konya where is the capital of Seljuk Empire in history has many historical buildings such as caravansary, madrassah, mosque and etc. These structures were helped to establishing the GCPs. The coordinates of GCPs were measured with GPS technique based on CORS-TR network. The GPS measurements have ellipsoidal heights (h). The orthometric heights $(\mathrm{H})$ of the GCPs were estimated with online calculations based on EGM08 geoid model (url-1).

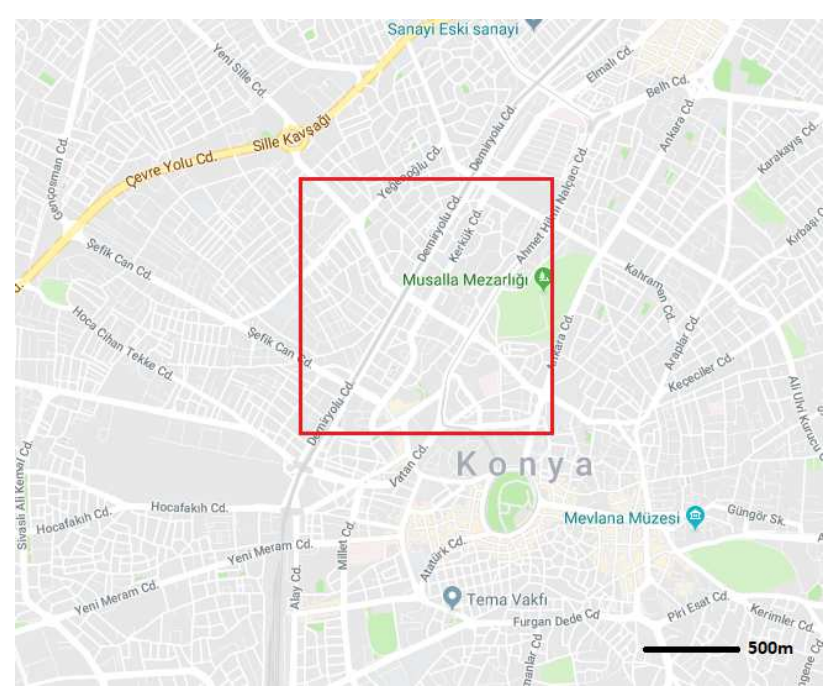

Figure 1. The study area. The centre is $37^{\circ} 53^{\prime} 2.4^{\prime \prime} \mathrm{N}$ latitude and $32^{\circ} 29^{\prime} 8.25 " \mathrm{E}$ longitude. (source: Google maps)
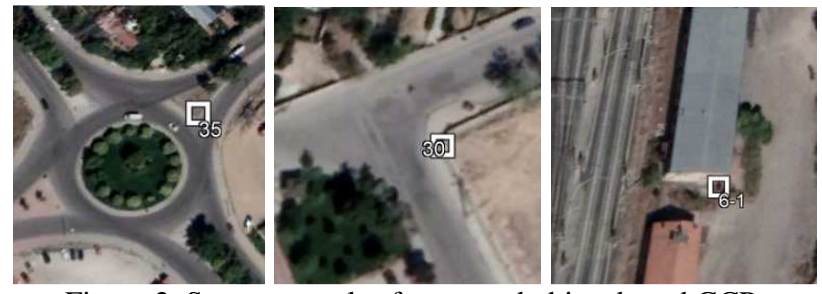

Figure 2. Some examples for created object based GCPs

\section{RESULTS}

\subsection{Point Cloud Creation and Registration}

Dense point cloud creation procedure uses a technique referred to as SfM to resolve feature positions within a defined coordinate system of stereoscopic images. SfM refers to a set of algorithms that includes the automatic detection and matching of features across multiple images. The camera parameters, image positions and 3D geometry of a scene are automatically determined by an iterative bundle adjustment (Peterson et al., 2015). The SfM procedure in photogrammetry is called many different names such as multi-view photogrammetry, dense point cloud extraction, and dense image matching. Most SfM software is able to calibrate a camera and create a 3D point cloud. Hence, this procedure does not require the camera to be 
pre-calibrated. Otherwise, pre-calibration of the camera was performed with a calibration sheet or grid area, which has known control points. Then the calibration parameters are estimated with an iterative bundle adjustment of the sheet or grid images taken from different perspectives.

The matching results are generally sparse point clouds, which are then used as seeds to grow additional matches. Then dense point cloud is generated with creating the coordinates for every matched point from all of the conjugated images. Currently, all available algorithms focus on dense reconstructions using stereo or other multi-view approaches. In this study, the image orientation and point cloud creation were executed by Photoscan (Agisoft, 2017) software (Table 2).

\begin{tabular}{llll}
\hline & Date 1951 & Date 1975 & Date 2010 \\
\hline Images\# & 2 & 3 & 2 \\
Flaying altitud & $6.27 \mathrm{~km}$ & $7.26 \mathrm{~km}$ & $8.05 \mathrm{~km}$ \\
Ground & 73.4 & 40.3 & 50.2 \\
resolution & $\mathrm{cm} /$ pixel & $\mathrm{cm} / \mathrm{pixel}$ & $\mathrm{cm} / \mathrm{pixel}$ \\
Coverage area & $27.6 \mathrm{~km}^{2}$ & $22.7 \mathrm{~km}^{2}$ & $21.7 \mathrm{~km}^{2}$ \\
Tie points & $1616 \mathrm{of} 1756$ & $6527 \mathrm{of} 6655$ & $3870 \mathrm{of3994}$ \\
Projections & 3232 & 13487 & 7740 \\
Reproj. Err. & 0.989 pixel & 0.867 pixel & 0.259 pixel \\
Max.reproj.err. & 5.804 pixel & 8.034 pixel & 1.910 pixel \\
Dense points\# & 2539040 & 8859870 & 5243623 \\
\hline
\end{tabular}

Table 2. Point cloud creation results

The registration of point clouds to geodetic frame was performed with measured object based GCPs. The selection of GCPs from two images is very hard due to image resolution and shadow effects. Whereas it can be selected easily from one of the images, its selection can be very hard from the other image. Nevertheless the registration could be done with enough number and uniform distributed GCPs (Figure 3). The registration accuracy was evaluated by root-mean square error (RMSE) of the residuals on the GCPs (Table 3). The overall RMSE in XY and XYZ space was acquired by Equation 1 and Equation 2 .

$$
\begin{aligned}
& R M S E_{x y}=\sqrt{\frac{\sum\left(x_{s}-x_{r}\right)^{2}+\sum\left(y_{s}-y_{r}\right)^{2}}{n}} \\
& R M S E_{x y z}=\sqrt{\frac{\sum\left(x_{s}-x_{r}\right)^{2}+\sum\left(y_{s}-y_{r}\right)^{2}+\sum\left(z_{s}-z_{r}\right)^{2}}{n}}
\end{aligned}
$$

where subscript $s$ and $r$ are show the coordinates measured geospatial and transformed on the aerial photo of the same point respectively. $n$ is number of GCPs.

\begin{tabular}{llll}
\hline & Date 1951 & Date 1975 & Date 2010 \\
\hline GCP\# & 6 & 7 & 6 \\
Image\# & 2 & 3 & 2 \\
RMSE X & 1.54 & 1.09 & 0.32 \\
RMSE Y & 1.60 & 1.03 & 0.52 \\
RMSE Z & 1.86 & 3.67 & 1.62 \\
RMSE XY & 2.22 & 1.50 & 0.61 \\
RMSE XYZ & 2.90 & 3.96 & 1.73 \\
\hline
\end{tabular}

Table 3. RMSE of residuals on the GCPs [units: $\mathrm{m}$ ]
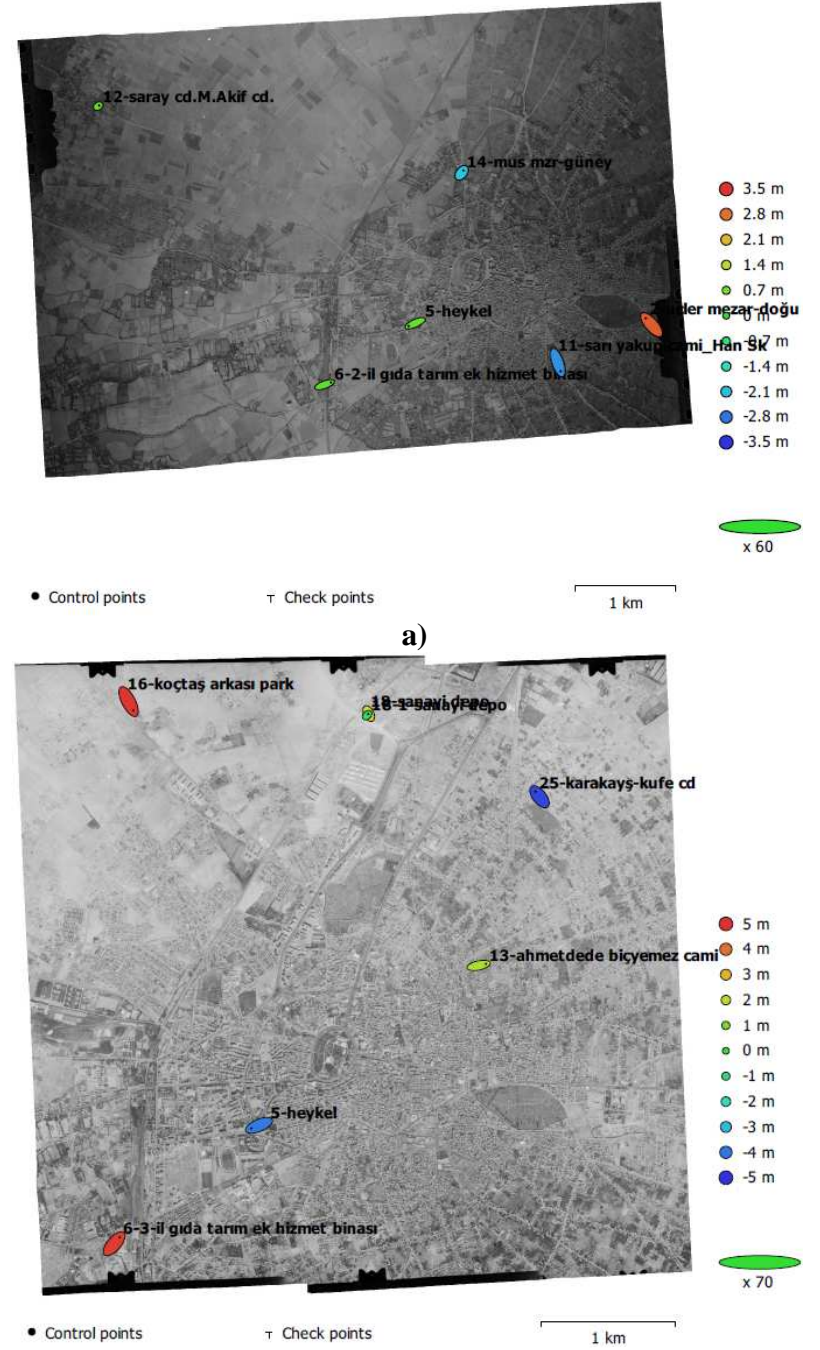

b)

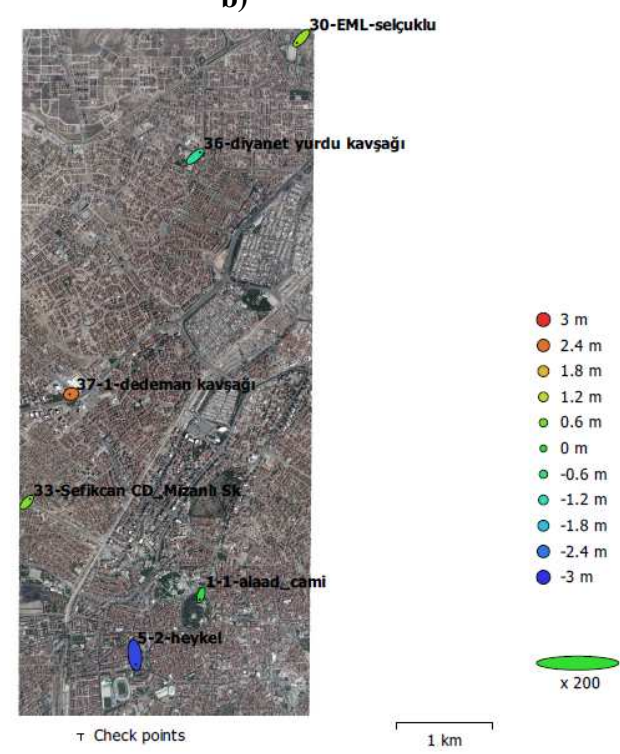

c)

Figure 3. GCP locations and estimated errors on orthophoto images. a) The year of 1951, b) 1975 and c) 2010

\subsection{Change Detection}

The study area was selected from common region of three time series point cloud data (Figure 4). It has 2.25 square kilometres 
with $1.5 \mathrm{~km} \times 1.5 \mathrm{~km}$ dimensions. The oldest date of the point clouds was selected as a reference and the other two point clouds were compared to its coordinate frame with ICP algorithm. The ICP uses closest point set to estimate registration parameters between the point cloud data set. The point clouds of the date 1975 and 2010 were registered into reference point cloud of the date 1951 (Table 4). The changes are estimated with distances between target points (date 1975 and 2010) to reference points (date 1951) or surface (triangle). The changes (or differences) between two point cloud data sets were estimated with distances from point to surface in this study. Before detection the changes, the each point cloud of selected area was interpolated to getting uniform space point data. Interpolation step was selected $0.50 \mathrm{~m}$ that compatible with average point spaces of the created dense point clouds (Table 2). After the interpolation, every point cloud has approximately nine million points that has about 4 points at per square meters. The urban area changes were estimated for date intervals of 1975 to 1951 and 2010 to1951 (Figure 5, and Figure 6).

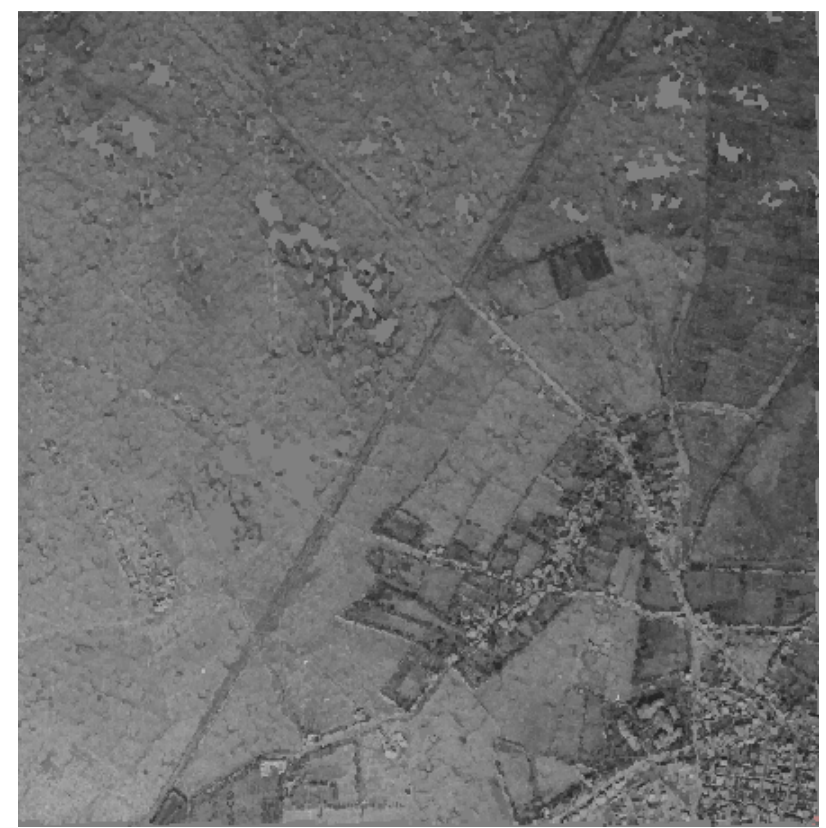

a)

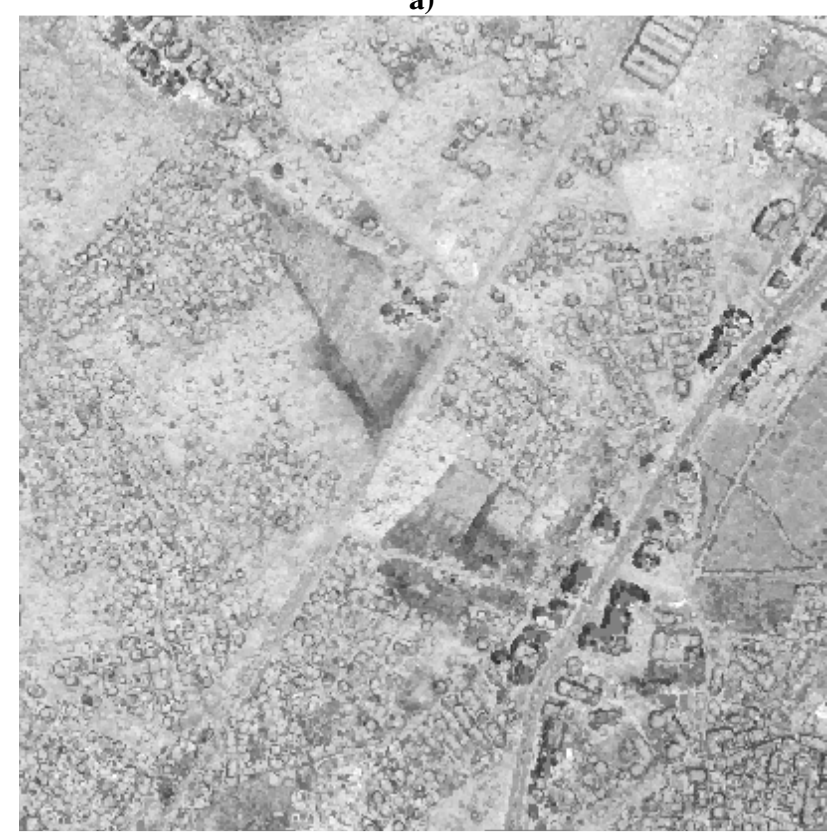

b)

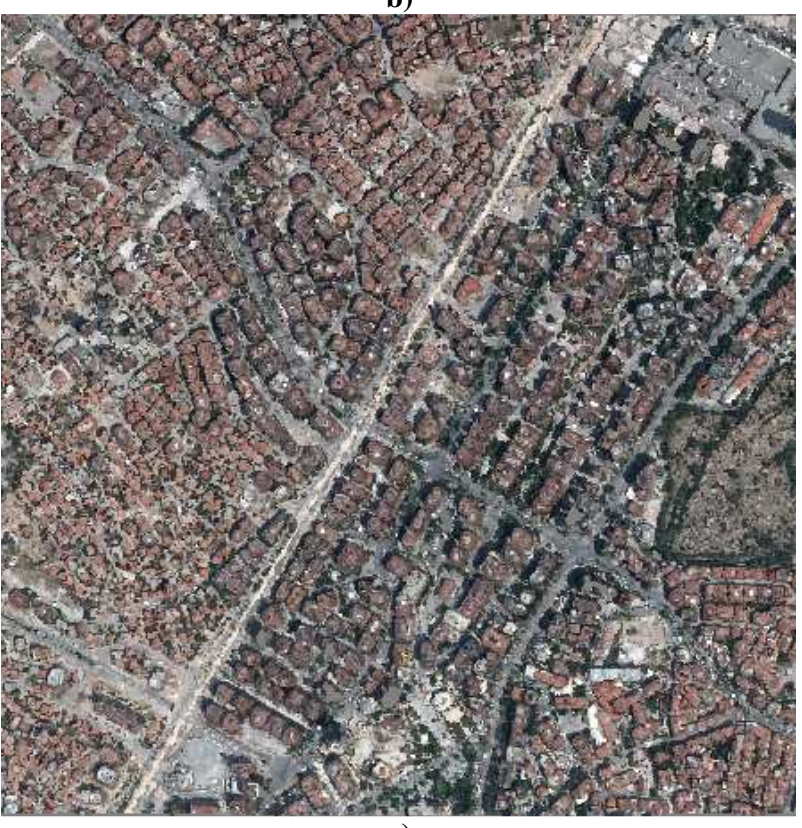

c)

Figure 4. Point cloud data of the study area. a) The date of 1951, b) 1975 , and c) 2010

\begin{tabular}{llll}
\hline $\begin{array}{l}\text { Data of } \\
\text { Year }\end{array}$ & Convolution & Mean & Std. Dev. \\
\hline $\begin{array}{l}1975 \text { to } \\
1951\end{array}$ & $8.4 \mathrm{e}-7$ & 0.000518 & 0.999201 \\
2010 to & $7.6 \mathrm{e}-7$ & 0.001169 & 0.994892 \\
\hline 1951 & & & \\
\hline
\end{tabular}

Table 4. The registration from 1975 to 1951 and 2010 to 1951 [units: $\mathrm{m}$ ]

\section{DISCUSSION}

The registration accuracy of point cloud is related with the number, distribution and type of the GCPs. The registration was done with enough number and uniform distributed GCPs. The accuracy is compatible with the point density. The residuals on the GCP are between 0.32-1.59 meters for XY coordinates and 1.62-3.67 meters for $\mathrm{Z}$ coordinates. The big residuals on $\mathrm{Z}$ coordinates are expected results because natural ground level had been changed with filling materials in urban area. Base/height ration of the stereoscopic images also effect the registration accuracy. The base/height ratio is $0.38,0.22$ and 0.19 from old to close date stereoscopic images respectively. Owing to the fact that the images had been matched with the large number of conjugate keypoints, the relative orientation was performed with high level accuracy. Many similar studies had been performed with the same level accuracy for the registration (Nebiker et al., 2014; Hughes et al., 2006). In addition, reprojection errors on the GCPs are one pixel level after the registration. On the one hand the residuals have not significant effect on the scale of point cloud. The estimation of urban changes do not affected from these small residuals of georeferencing since the change detection in this method is based on relative comparison of the point clouds.

The point clouds of date 1975 and 2010 were registered into the reference point cloud of date 1951 with one meter standard deviations. After the registration, the mean distances between the point clouds in these registrations are close to zero (Table 4). 
The expected changes in the study area are in positive directions, and the estimated changes verify this expectation. The changes in below direction are in slight area, where they were resulted from demolished buildings (Figure 5).

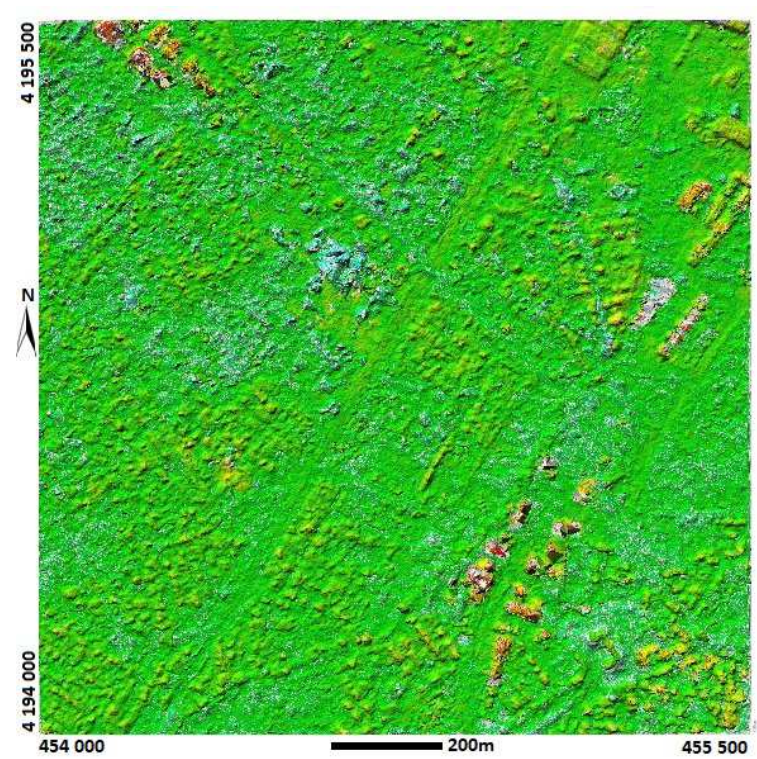

a)

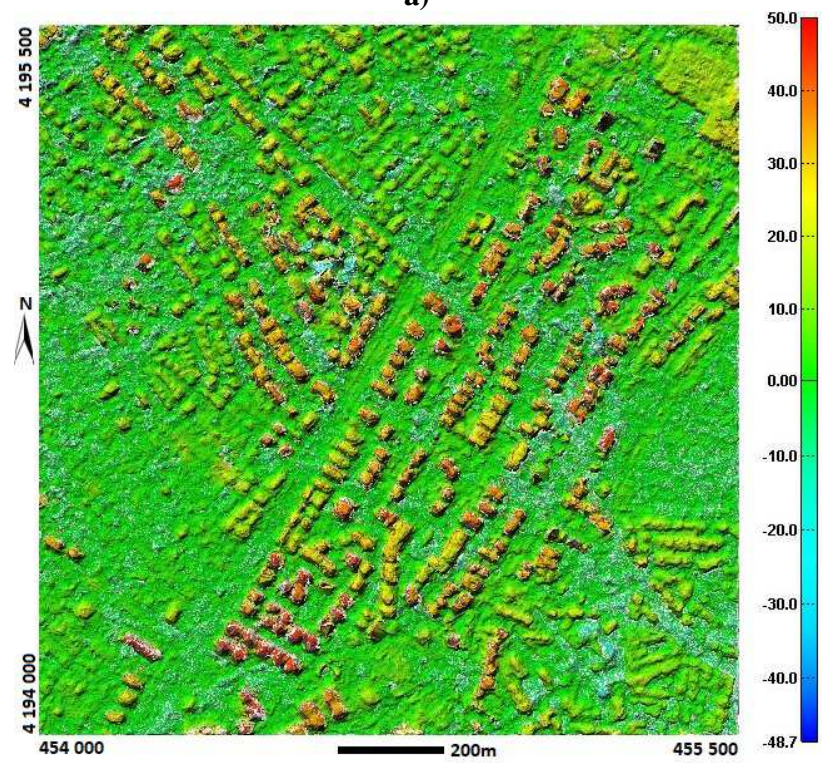

b)

Figure 5. a) The changes between date of 1951 and 1075, b) The changes between date of 1951 to 2010 . Colour legend shows height differences. Left below corner is on $37^{\circ} 52^{\prime} 38.03^{\prime \prime} \mathrm{N}$ latitude and $32^{\circ} 28^{\prime} 37.73 " \mathrm{E}$ longitude geographical coordinates [units: $\mathrm{m}$ ]

\section{CONCLUSION}

Dense point cloud from structure from motion photogrammetry has a large variety of application areas. In this study urban area changes were detected by using dense point cloud created from historical aerial images. The point clouds were compared by registering with ICP algorithm. The point to surface distances indicated the changes between the point clouds belong two dates. The method is practical way to detecting the changes in urban area. Moreover grooving technology of unmanned aerial vehicle can be used for imaging and change detection with short time interval in urban areas. The accurate and up-to-date change detection offers decision making efficiently to the authorities for planning and administrating.

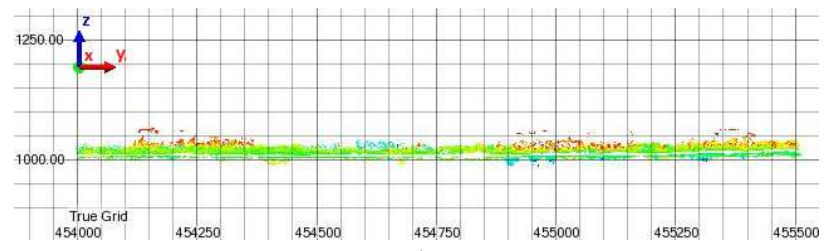

a)

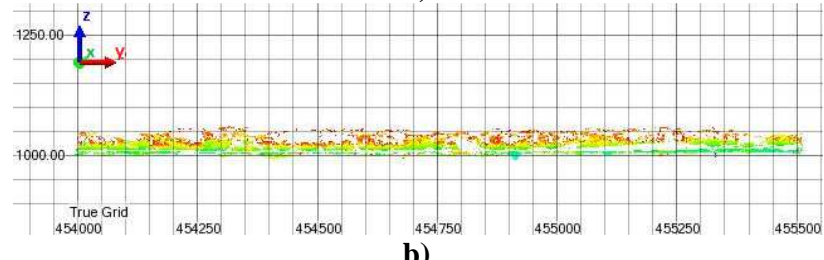

b)

Figure 6. Change visualization from perspective on $-y$ axis. a) The changes from 1951 to $1075, b$ ) The changes from 1951 to 2010

\section{ACKNOWLEDGEMENTS}

This study was supported for the project (17401062) by Scientific Research Found (BAP) of Selcuk University.

\section{REFERENCES}

Agisoft, 2017. Photoscan Professional (ver:1.3.2.4205)

Awrangjeba, M., Fraser, C.S., Lua, G. 2015. Building change detection from lidar point cloud data based on connected component analysis. ISPRS Annals of the Photogrammetry, Remote Sensing and Spatial Information Sciences II-3/W5, pp. 393-400

https://doi.org/10.5194/isprsannals-II-3-W5-393-2015

Barnhart, T.B., Crosby, B.T., 2013. Comparing two methods of surface change detection on an evolving thermokarst using high-temporal-frequency terrestrial laser scanning, Selawik River, Alaska. Remote Sensing, 5(6), pp. 2813-2837. doi:10.3390/rs5062813

Barazetti, L., Scaioni, M., Remondino, F. 2010. Orientation and 3D modelling from markerless terrestrial images: combining accuracy with automated. The Photogrammetric Record, 25(132), pp. 356-381

Chen Y., Medioni G., 1192. Object modelling by registration of multiple range images. Image and Vision Computing, 10(3), pp. $145-155$

Du, S., Zhang, Y., Qin, R., Yang, Z., Zou, Z., Tang, Y., 2016. Building change detection using old aerial images and new LiDAR data. Remote Sensing, 8(12), 1030; doi: $10.3390 / \mathrm{rs} 8121030$

Harwin, S., Lucieer, A., 2012. Assessing the accuracy of georeferenced point clouds produced via multi-view stereopsis from unmanned aerial vehicle (UAV) imagery. Remote Sensing, 4(6), pp. 1573-1599, doi:10.3390/rs4061573

Hughes, M.L., McDowell, P.F., Marcus, W.A., 2006. Accuracy assessment of georectified aerial photographs: Implications for measuring lateral channel movement in a GIS. Geomorphology,74(1-4), pp. $1-16$ 
Jensen, J.L.R., Mathews, A.J., 2016. Assessment of imagebased point cloud products to generate a bare earth surface and estimate canopy heights in a woodland ecosystem. Remote Sensing, 8(1), 50; doi:10.3390/rs8010050

Nebiker, S., Lack, N., Deuber, M., 2014. Building change detection from historical aerial photographs using dense image matching and object-based image analysis. Remote Sensing, 6(9), 8310-8336, doi:10.3390/rs6098310

Peterson EB, Klein M, Stewart RL (2015) Whitepaper on structure from motion (SfM) photogrammetry: Constructing three dimensional models from photography. Technical Report (ST-2015-3835-1), U.S. Department of the Interior Bureau of Reclamation Research and Development Office, 46 pages

Scaioni, M., Roncella, R., Alba, M.I., 2013. Change detection and deformation analysis in point clouds: Application to rock face monitoring. Photogrammetric Engineering and Remote Sensing, 79(5), pp. 441-455
Tran, T.H.G., Ressl, C., Pfeifer, N., 2018. Integrated change detection and classification in urban areas based on airborne laser scanning point clouds. Sensors 18(2), 448, doi: $10.3390 / \mathrm{s} 18020448$

Xiao, W., Vallet, B., Brédif, M., Paparoditis, N., 2015. Street environment change detection from mobile laser scanning point clouds. ISPRS Journal of Photogrammetry and Remote Sensing, 107, pp. 38-49

Zhang, X., Glennie, C., Kusari, A., 2015. Change detection from differential airborne LiDAR using a weighted anisotropic iterative closest point algorithm. IEEE Journal of Selected Topics in Applied Earth Observations and Remote Sensing, 8(7), pp. 3338-3346.

url-1: https://geographiclib.sourceforge.io/cgi-bin/GeoidEval 